\title{
Pure Fiji Export Limited: A Skin Care Company In Harmony With Nature And Culture
}

\author{
Carol Frodey, (Email: Frodey@connect.com.fj), University of the South Pacific, Fiji
} Yamini Naidu, Australian Department of Aboriginal Health, Australia

\begin{abstract}
Pure Fiji is a privately-held, Fijian-owned company providing quality, USA niche market, botanical skin care products, while passionately concerned for the local environment and development of rural women in Fiji. This paper explores the company's success factors and its contribution to local development, while establishing a profitable, rapidly growing company with an international reputation for its environmentally friendly, botanical products targeted at the rich and famous, particularly in the USA. The paper also explores Pure Fiji's international expansion approach, which is cautious and based on careful supplier selection and relationship management.
\end{abstract}

\section{INTRODUCTION TO THE CASE FROM 2002}

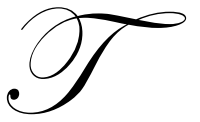

he excitement in Mrs. Gaetane Austin's voice was unmistakeable; her daughter Danielle (who is also the factory manager) was in America to showcase the Pure Fiji products at the 2002 Emmy PreAward Night Beauty Buffet and things were going as anticipated. She stated passionately, "Ours is a most incredible business because we touch people, physically, and emotionally and change their lives". The Austin women have good reason to feel proud as they have created history by being the first solely female owned company to win the Fiji Prime Minister's Exporter Award.

The Prime Minister of Fiji stated at the Exporter of the Year awards: "Pure Fiji Export Limited may not be one of Fiji's largest exporters but obviously has the potential to become one of Fiji's unique success stories". (The Review, 2001: 32)

\section{BACKGROUND AND RECENT DEVELOPMENTS THROUGH 2006}

Pure Fiji is locally owned, was formed in 2000 as the export arm of Sandollars, and is a Limited Liability family owned company. The company started with an investment of $\$ 8,000$, and presently boasts an investment in excess of FJ $\$ 5,000,000$. Initially they were involved in production of gift products mainly, adult "Amenity Kits" for inflight use on Air Pacific International Flights. Other products included carved wood for business card boxes, note paper holders, pen cups, picture frames, etc. Then, their primary clients included Air Pacific, Royal Tonga Airlines and the Sheraton Resorts.

"Entrepreneurs are individuals who recognise opportunities where others see chaos or confusion." (Kuratko, Hodgetts, 2001: 4). This is an apt quote to explain the dramatic success of the company following the 2000 political coup in Fiji, which temporarily brought their business to a standstill. The birth of Pure Fiji Export Limited took place during one of the worst economic periods of Fiji's history, following the 2000 attempted coup and has become a success, adding to Fiji's reputation as a country that provides high-quality, up-market, environmentally friendly products, alongside companies such as Fiji Water, Pacific Green Furniture, and Wakaya Club Resort. 
Making the business successful overseas has required the owners to work seven days a week, skipping holidays and making many personal sacrifices to revive the business. They still do not take a salary, but roll all the profit back into the growth of the company.

\section{SANDOLLARS}

The original company, Sandollars, was set up in 1995. It all started when Gaetane's daughter Andree arrived home in 1995 from America where she was working as a top executive in a hotel chain. In Fiji she saw rich natural resources, a high potential to manufacture high quality soaps, oils, and lotions for the tourist market through harnessing the skills and raw materials available to the women from the interior and squatter villages. Mrs Austin vividly narrates an image that sparked the idea for natural Fiji made products. She comments: "A pickup truck was unloading all these beautiful rolls of vau and the sun was playing on the vau and I thought we have so much natural beauty. We looked around and said: My God there are all these traditional arts, magi magi (coconut fibre used to make sinnet), vau (leaves used to make ribbon) and voivoi (leaves used for making mats) and beautiful weaving that the women do." No one was actually doing anything with it or harvesting their skills. Andree decided to stay back and work on this. In 1995 Gaetane and Andree Austin registered the company under the name Sandollars.

Mrs Austin, together with her daughter Andree, decided to produce locally made pressed soap. As they did not have facilities for manufacturing, they arranged for a major local manufacturer to produce the products for them. All the packaging of the product at the initial stage took place in the family kitchen and those early days were chaotic as the workers took over the kitchen, eliminating family privacy. A line of soap and coconut oil were designed and named Waiwai ni Viti (oil) and Sovu ni Viti (soap). The first batch of 12 soaps were taken by Tappoo's, a major upmarket local retailer, and within weeks the orders grew from 12 to 24 to 100 to 500 and then Tappoo placed a $\$ 20,000$ order. The demand for the product was so great that the company had a hard time keeping up with orders. The Austin ladies decided early on to create a niche market for their product as a luxury good item

targeted at up-market consumers. They have firmly resisted requests from large discounters such as Walmart to carry the product line. Daughter Danielle joined the company a few years after start-up as factory manager.

\section{PURE FIJI}

In 2000 Pure Fiji was registered as the Export company, with the sole intent to export their product to markets, such as America, which Andree knew well from her years working there in the hospitality industry. Sandollars concentrated on servicing the local market. A few years later, son Alexander returned to Fiji from America to join the company, and just this year (2006) daughter Sophia who is a Bachelor of Digital Media and living in Australia, has jointly taken on the Pure Fiji distributorship for Australia (with her partner). This company is truly a family success story.

After their humble home beginning, the company sublet space in another nearby factory. In September 2001, when the business had grown significantly, the company moved into their own factory through a bank loan. Their rapid growth caused them to outgrow their new factory and in November 2004 they moved into their own custom built building, an attractive upmarket looking factory facility in the same industrial subdivision, surrounded by beautiful gardens, whose products are also used in the spa!

\section{PURE FIJI SPA}

The new building incorporated a luxury skin and nail care spa for customers, which is, more importantly, used to train spa and salon employees around the country in the use of Pure Fiji products. The spa has set a new level of spa luxury in Fiji, not even matched by top resort spas. The entrance to the spa is in front of the building, separated visually from the factory. One enters the spa across stones set over flowing water, to leave one's shoes outside the inner sanctuary. Inside, the guests are comfortably seated, their feet are immersed in a copper bowl of warm water with coconut milk bath to soak, while they unwind and sip a cup of lemon grass tea from the Pure Fiji gardens. Guests are asked to arrive fifteen minutes early to experience this unwinding ritual and prepare themselves for more luxury to come. 
Spa services are varied but all aimed at skin, body and nail care with luxury. One must go somewhere else for painful waxing or hair cuts! Their unique hot stone massage is a first for Fiji, with more traditional massages and aromatherapy massages also available. Massage/facial/body wrap rooms are spacious and equipped with the most modern equipment and amenities. The shower room is another touch of luxury, for those needing to shower off some of the oil before leaving. The manicure/Pedicure room is equipped with a state-of-the-art massage chair, customer controlled, accompanied by soft music, and incorporating a self-sanitizing foot spa with water jets and other magic. Special callus removal lotion complements their service, leaving feet soft and moisturized with the company's body butter warm foot or hand masque, as well as trimmed nails and a new coat of polish. Sanitation and hygiene are emphasized in all aspects of their operation.

\section{PRODUCT RANGE}

The company produces products under the Reniu brand, Mana'ia and the Pure Fiji brand, their more upmarket Spa line. Hand made paper products supplement their product line and are also used for gift-wrapping and making bags for company products. The products are mainly sold under the labels Reniu and Pure Fiji and initially included tropically fragranced soaps, body oils, lotions, creams, and a raw sugar and coconut oil body rub. Newer products include coconut oil shampoo, conditioner, bath gel, and body scrub lotion (2005), along with a line of facial care products (2006). All products focus on using natural Fiji products and botanicals. Generally Reniu branded products are made from pure extra virgin coconut oil, while Pure Fiji products use the same coconut oil blended with exotic tropical nut oils. All have infusions of high quality tropical fragrances.

The body care products come in a number of different fragrances: coconut, frangipani, tiare (gardenia), senimoli (orange blossom), pineapple, starfruit, passionflower, and watermelon. While all products are available in a variety of scents, not all scents are available in every product line. They have also introduced a line of male skin care in the Mana'ia fragrance.

Packaging is attractive and functional: designed for ease of dispersion and minimal contamination with use, with the lotions having clear palm-press dispensers. Most products come in $2 \mathrm{oz}(59 \mathrm{ml}), 8 \mathrm{oz}(240 \mathrm{ml})$ and $16 \mathrm{oz}$ $(472 \mathrm{ml})$ sizes. The products are made from high quality ingredients that are sourced locally wherever possible, and are in keeping with today's environmental concerns and are thoroughly biodegradable. The bottles and jars with laminated water/oil resistant labels were originally created in America, as similar quality is not locally available, but the labels are now produced closer to home in New Zealand. The product design is tested at prestigious fragrance laboratories.

The primary product ingredients include the following:

$$
\begin{gathered}
\text { Raw Materials } \\
\text { Pure Fiji Coconut Oil } \\
\text { Sodium Hydroxide } \\
\text { Carboxyl Methyl Cellulose } \\
\text { Pure Water } \\
\text { Potassium Hydroxide } \\
\text { Fragrance }
\end{gathered}
$$

\section{PAPER PRODUCT AND HANDICRAFT PRODUCTS}

Pepa ni Viti (paper made in Fiji) is hand made paper that is made into stationery, folders and wrapping for other products. Extra pieces of material are used to add value to the product with items like creative collages, and nothing goes to waste. 


\section{OTHER ACCESSORIES}

Pure Fiji has also introduced accessory items such as scented sticks which can be dipped in aroma therapy oils, scented folding fans, hair accessories, and other unique items.

\section{STATUS AND STRUCTURE OF THE FINANCIAL INVESTMENT INTO PURE FIJI (Source: Interview By Sonal Singh With The Directors}

Pure Fiji Ltd

Limited Liability Company

Registered - 1995 Sandollars Fiji Ltd,;

Registered - 2000 Pure Fiji Export Limited.

Shareholders:

Ms Gaetane Austin -50\%

Ms Andree Austin -50\%

No Partnership Agreements

No foreign partners

Annual turnover and profitability figures are not available for this closely held family company.

BORROWING STRUCTURE - LONG TERM LOAN WITH ANZ BANK.

Total estimated value of investment in company: FD $\$ 5,000,000$

EQUIPMENT TOTAL VALUE OF EQUIPMENT FD\$1,000,000

Initial Establishment Costs 1995 - FD $\$ 8,000$

\section{DESCRIPTION OF INVESTMENTS}

Infrastructure - Building Value Property/Plant \& Equipment stands at FD5,000,000. The company operates from a building in Vatuwaqa which is being purchased but is under Mortgage.

The majority of production is carried out by manual labour with the exception of mixing machines and labelling machines and filling line.

Instilled capacity - One shift

The 2 Directors now receive a very minimal salary as money is ploughed back into the business as investments.

\section{OPERATIONS MANAGEMENT}

The new factory is much larger and more high tech than previous factories. To keep products uncontaminated, one must tour outside looking though the big glass windows. While proud of their new equipment, they are never one to forget their humble beginnings. The Austin's have, therefore, kept most of their workable machinery which is older and smaller and harder to maintain. They have also found them useful for small product runs. This ranges from mixing vats to labelling machines. While they purchase local virgin coconut oil, which is classified as filtered, they have found that it does not come near meeting their rigid standards, so have special oil 
tanks, where the oil can settle, and impurities can be drained off, leaving crystal clear oil for use in their products. Pure Fiji has the only state-of-the-art cosmetic manufacturing factory in Fiji which includes water sanitizing and filtering equipment. Therefore all water used in their products is pure and uncontaminated. They have been using buckets to transfer the water to the mixing vats, but have now converted that system to piped water right from the filtration source to the vat, eliminating both manual work and possible contamination. Oil and water are heated to 80 degrees centigrade for mixing and are then cooled down over about two days to a temperature of about 25 degrees centigrade for fragrancing and filling. All of this is done under strict quality control. Following filling, the products are labelled, and packed for shipping.

\section{QUALITY CONTROL}

The process of quality control is taken very seriously. The production is scheduled so that a particular product is produced at each time or each day. For each production batch the raw materials are inspected and a sample is kept for testing before production begins, tests are also done for $\mathrm{pH}$ levels and a report is made and kept together with a sample of the finished product. As Andree, points out, "We have to know every little detail if something goes wrong; the American market is a very fussy customer". There are two units of all sensitive electronic equipment such as ph meters, tamper proof machines, small scales etc. so when one is sent overseas for repairs or re-calibration, the other is used.

The quality inspection on the finished product is done personally by Danielle the factory manager. "Danielle has such an eye for detail she will see defects in labelling, that we wouldn't even notice, and discard the product straight away as we want everything to be perfect; our customers demand this." Gaetane makes this statement as she explains the drive for quality is challenging as Fiji has a culture of: "that will do", a policy the company adamantly does not accept.

\section{QUALITY STANDARDS}

The company has to comply with the same standards that the Food and Drug Administration have in the United States and this requires the factory to be sealed off and air conditioned. The factory maintains the same "good manufacturing practices" as Australian pharmaceutical standards and ISO. All batches are made in small batches, allowing the company to monitor the production process and maintain superior quality and freshness. According to Danielle the three things that the guest nominees liked at the Emmy Awards' 'Pre-Emmy Salon' was that the product was from Fiji, natural, and that it was a quality product.

\section{JUST IN TIME MANAGEMENT}

Gaetane explains, "we did not want to go for the pennies and that meant that we were not going to go into mass production. "The exclusiveness of the market has been an essential element in how the products have been produced, priced, and marketed.".

Every Thursday the suppliers from the villages and settlements bring their supplies to the factory, and they are paid in cash for their products. Fridays are kept for the shipment of orders before the week-end. Production is based on par levels in the inventory of finished product., export orders are shipped airfreight on a weekly basis, or in sea freight containers as needed.

The company started air freighting their products to USA (their major market) after attending a seminar by DHL on the cost saving benefits of air freight at a Fiji Trade and Investment Board (FTIB) seminar. DHL highlighted that through airfreight, a company would not have to tie their dollar up in inventory during shipping and in providing safety stocks with each distributor. This enabled Pure Fiji Export Limited to keep a small inventory but still quickly meet their market's demand. With dramatic growth in production with the new factory and skyrocketing product demand from numerous markets besides America, particularly Australia and new Zealand, their shipment policies have changed. Better able to anticipate sales demand with experience and stabilization of 
distributor relationships, and facing high product demand a significant amount of product is now shipped by sea in 40 foot containers. Air freight is still used for small or emergency orders, to prevent customer disappointment.

\section{HUMAN RESOURCE MANAGEMENT}

Pure Fiji Export Limited is a family affair. Gaetane and Andree Austin are the co- owners, with Andree involved more in researching new ideas on product development, promotions and tradeshows and maintaining the website. Gaetane, on the other hand, seems to deal most with the local suppliers and distributors. Daughter Danielle is the factory manager and sees to the smooth production process, while also representing the company at special events like the Golden Globes, Emmies, and Grammys pre-event services for the nominees. Danielle also runs the spa. Alexander plays a major role now in the production process and Inventory control.

The company has around 30 staff, two of whom are piece workers (paid per unit of production), making bags, wrapping soap. They have found that piece workers have significantly higher productivity, but only certain types of jobs lend themselves to piece working. There are approximately 500 people employed as 'piece workers' outside the factory. These help to provide the coconut and other nut oils, making the hand-made paper, and weaving baskets for packaging. Gaetane takes a personal interest in her staff providing them with daily vitamins and clean facilities. The bathroom facilities can be compared to those in upmarket hotels and staff are strongly encouraged to maintain a high level of hygiene.

All the staff are on the national pension scheme. Although staff do not have a health plan, the company foots bills for their medical expenses when they are sick. Although there is no structured staff recruitment, Gaetane has been able to identify people who are good workers. She tells the story of her gardener who used to help around the factory and became the laboratory assistant. Staff turnover is very low, as a result of her efforts to provide a comfortable and rewarding work environment. Many employees have remained with the company for ten years, since the humble beginnings in the family kitchen.

\section{Labour}

Australian Cosmetic Chemist Consultant.

This is the only expatriate.

All other 32 employees are Fiji citizens, including Austin family members.

\section{Skill Level}

All the factory workers are unskilled. Most came straight out of school or from jobs totally unrelated to the cosmetic industry.

There are four Spa therapists who initially had minimal training but have been constantly trained by professional trainers in the Pure Fiji Spa

Included in the 32 factory employees are three full time cleaners and laundry workers

\section{SUPPLIER RELATIONSHIPS}

The idea to harvest local skills was one important aspect but critical to the business was the constant supply of raw materials that would sustain their production. This lead to the Austin's having village to village co-operatives for the paper making and basket weaving. Other villages make masi, oil, magi-magi and vau. Residents of an urban settlement, (Tuirara) in Suva make baskets, voivoi ribbons and little flower craft; these women are from the Lau group that is famous for beautiful handicraft creations.

The locally produced paper is a remarkable achievement as it has created a sustainable livelihood for a group of Fijian women in an interior village of Namosi. Initially importing packaging paper from Indonesia, the Austin's thought this was ridiculous when the same resources would be found locally. To teach the villagers how to make world class paper, a consultant was recruited with the help of the New Zealand High Commission and the 
Centre for Development of Enterprise in Brussels. Two projects were under taken: one in a village in the interior of Viti Levu and another on the island of Vatulele. The consultant, an art teacher from New Zealand, was welcomed like a member of the village. The interior village embraced the project. They now produce sometimes 5000 sheets of paper per week for the company. The Vatulele endeavour was not as successful, probably due to more availability of alternative money-making activities in tourism on that island.

Not only was the skill of papermaking taught but the women were also given training on how to keep receipts and manage accounts. On one visit to the factory in the early days of paper production, the women were asked if they were keeping any money aside for maintaining their generator. Although they were not doing so at the time, they now put $10 \%$ of their revenue aside for the maintenance of their machines. When the men of the village, sensing good earning potential, wanted to take over management of the project, the Austin's strongly objected, telling them they that would not buy any paper if the men took over as it had been conceived as a project for women to give them financial independence and the ability to provide education and quality of life for their children and families.

Building supplier relationships from scratch has not been an easy task, especially when culture takes precedence over production matters.

\section{THE IMPACT OF CULTURE}

"Neither culture nor sustainable development are steady-state phenomena. They both change, and new problems and new solutions call for continuous attention: the important thing is to understand the importance of both culture and sustainable development, as well as the relationship between the two" (Kavaliku, 2000: 27)

A critical element in the relationship with their suppliers has been that they have understood the supplier's cultural obligations and successfully deal with them. Gaetane related the dramas sometimes involved in getting products produced on time for major events. For the Emmy Awards, the company was presenting their products in a basket to give it a unique look. The village producing the basket was given six weeks but due to a funeral in the village, the delivery schedule went haywire and everything came to standstill, as the women were required to help in preparations for the funeral. To help compensate for unexpected cultural obligations, the company always sets false deadlines, and this bought her time but the process of weaving was so slow that for three weeks she had to make daily trips to collect the baskets and encourage the women to keep up with the deadline.

\section{DISTRIBUTOR RELATIONSHIPS}

The Austin's have learned some hard lessons, early on, with their distributors. They now place great emphasis on careful selection of distributors. They emphasize the need to have a good understanding of each of their markets, and to be in constant communication with their distributors to assist and support them as needed. They are delighted that their daughter Sophia has taken over the Australian distributorship. Distributors are also used to help determine the priority of new products in the development process. Distributors are closest to the customer and in the best position to estimate relative demand. The Austins also invite their Distributors to come to Fiji and experience the spirit of Fiji. Without this initiation, they feel that the Distributor cannot completely understand and 'sell' Fiji. In fact, the company encourages a passionate involvement in Fiji.

\section{DISTRIBUTION CHANNELS}

From the beginning, the Austin's decided that the market niche for their product would be specialty luxury goods and they would look for customers at the higher end of the market. They wanted their range of products to be displayed only at outlets that reflected this image.

Locally the company sells its products through the finer stores and tourist hotels. The factory also sets up a factory outlet for three hours inside the factory every Saturday to meet the needs of local customers who cannot get the products they want from the local distributors. The product is often in short supply at many Suva outlets, due to 
high demand. They do not advertise locally, as ample demand is generated by 'word-of-mouth'. Prices at the factory are marginally less expensive than in the shops.,

Internationally the company distributes it's products using e-commerce and have a beautiful but simple website (www.purefiji.com). Most people have found out about their products through the Internet. Pure Fiji has also started to use exclusive retail outlets in the US, and in the Spas and boutiques of prestigious hotels such as the Bellagio, Wynn, and the Ritz Carlton chain of Hotels. Pure Fiji has just changed their distributor in Australia (daughter Sophia) and will now be making a major move into that market. They are also looking at other potential markets, but are determined to take expansion slowly and carefully, to manage growth in a controlled manner that does not place excessive stress on the company's operations, finance and quality control.

\section{E-COMMERCE}

Pure Fiji, from the initial stages, has been using the Internet to market products. This has provided them a venue to get into markets that otherwise would have been difficult to capture. "The Internet compels managers to speed up some activities, such as product development and launches; others, like strategic planning processes, can operate on more normal time." (Yoffie, Cusumano, 1999:81). This strategy has helped Pure Fiji quickly launch products, which has been one of the essential contributors of their success. Their new line of facial care products has seen such high demand from the USA that availability is very limited in Fiji at this point, while they test, stabilize and increase product production of such new products.

The web site is managed by Andree who constantly updates information on the site. The site has been made to be user friendly and, even with the pictures on the site, it is quick to upload. The product pictures can also be enlarged to show the products in real size and this helps customers who can't really touch or feel the product. Information is also provided about how the products are made, what is used and how the production of the products affects the environment.

Using the Internet has also increased the customer base; the selection of the product as a gift item for the Grammy and Emmy awards has been through the Internet. Event co-ordinators used the Internet to search for products and decided to use it after a trying the products on themselves and informing others about the product. A website also acts as an electronic brochure for the company.

\section{WORD OF MOUTH}

Recommendation from customers to potential customers has had major positive impact on sales of the product. It has been the driving force for the company's international recognition, since people get information about the product through someone they trust and know.

"Positive WOM has been recognised as a particularly valuable vehicle for promoting a firms products and services. Indeed, given its non-commercial nature, WOM communication is viewed with less scepticism than firminitiated promotional efforts" (Herr et al., 1991)

Pure Fiji Limited has been able to create positive word of mouth through the distribution channel that they have used. As they did not utilise many other promotional activities to create awareness of the product, outside of trade shows, potential customers have used existing customers as a source of information about the product. Word of mouth has also given the product a credibility that would have been hard to build through venues of promotion.

It has helped that the product is of such good quality that customers are eager to spread positive word of mouth. 


\section{CONTRIBUTORS TO SUCCESS}

"If you want to sell to the big boys, then you must have the same practices and processes that the big boys and leading cosmetic companies have", Andree made this statement in a interview for "The Review" magazine. Quality has been an important aspect for Pure Fiji products and the company always rejects products from their suppliers if they do not meet their quality standards. "We pay attention to detail, in our packaging as well as in product design and quality," states Gaetane.

\section{ENVIRONMENTALLY FRIENDLY}

Customers are becoming more environmentally aware, especially in the United States. Globally there is a great drive to create products that do not exploit the resources of the planet. Pure Fiji products are made from naturally sourced ingredients and these ingredients are biodegradable and preservative-free. Gaetane highlights the fact that they do not waste anything and make things, such as decorative packaging material for gift packs, out of the smallest scraps. Recycling of the bottles is encouraged and refilling of bottles is encouraged by local customers; techniques used for producing the products are designed to minimise harm to the environment. On their website under technical information, explanations are given as to why a particular technique has been used to produce different products. In addition to producing environmentally friendly products, the company has emphasised the development and empowerment of poor Fijian women.

The base ingredient for all Pure Fiji products is Virgin Coconut Oil, which is sourced from Fijian villages. The company is now also adding local nut oils to their Pure Fiji product line, which is also sourced from Fijian Villages. The benefits of Fiji nut oils for health and beauty care has been authenticated in research, according to the company, and have attracted large sales in the US Market. Pure Fiji is now working on additions to their existing range of products using other local ingredients, which to date have never been used in commercial manufacture.

The gathering and processing of these nut oils and other local ingredients will further increase employment in the rural areas. The involvement and empowerment of people at the grassroots' level is an important facet of Pure Fiji operation. About 500 villages from the surrounding areas are the supplier of the raw materials for products and packaging materials.

\section{COMPETITIVE ENVIRONMENT}

In Fiji, the company's niche market positioning and conveniently located weekly Saturday factory shop, leaves it with little direct competition. Companies in the coconut-oil-based skin care business locally include Mokosoi, Natural Oils of Fiji, and Punjas 'Naturally Fiji'. However, in the overseas markets, the company fully realizes that their competition includes all the major skin care companies. Also Mokosoi is exploring export opportunities and could become a local competitor over the long term. The company is not resting on its laurels and just enjoying its success. They are working hard to improve their products, introduce new skin care products demanded by their customers, and maintain their creative packaging and presentation.

\section{MARKETING COMMUNICATION}

Andree Austin, a co-owner of the company, points out that they do not have money for promotions apart from advertising through the in-flight magazine. How does a company that does not put much effort into promotion receive such tremendous international recognition? Locally, the company prefers to get publicity through donations, where acknowledgement of sponsors is given in the media. Thus, says Gaetane, we know we are supporting a worthy cause which contributes to local charities, and in giving we receive publicity.

Pure Fiji has also identified that it is important that constant participation in Trade Shows will assist the company in marketing it's products. They have witnessed that Trade Shows in the US are quite expensive but worth the cost. It has also been shown that Trade Shows of this nature are very effective for niche marketing. Participating in past Trade Shows has certainly benefited the company. 
The spa is also a highly effective marketing tool, as it trains resort and salon employees in the use of its products, ensuring that more Pure Fiji products will be adopted and used properly. Satisfied spa customers are likely to enquire as to the source of such high quality products.

The following factors have also assisted in strategic and selective marketing.

\author{
AWARDS: \\ - $\quad$ 1997: Exporter of the Year Award (General) \\ - $\quad$ 1998: Exporter Of The Year Award (Unique) \\ - $\quad$ 1998: Innovative packaging prize -1998 in a soap and cosmetics competition in the United States. \\ - 1999: Excellence in Tourism Award \\ - 2000: Exporter of the Year Award to the USA \\ - 2001: Exporter of the Year award (Prime Minister's) \\ - 2002: Exporter of the Year Award (USA) \\ - 2003: Fiji Chamber of Commerce Award: Most Innovative Company \\ - 2003: Business Woman of the Year Award \\ - 2003: Excellence in Tourism Award \\ - 2003: Exporter of the Year Award (Prime Minister's) \\ - 2004: Exporter of the year to USA Award \\ - 2004: B.I.D. Century International Quality Era Award - Gold \\ - 2005: Exporter of the Year to USA Award
}

\title{
MEDIA PUBLICITY
}

The company has received such extensive publicity overseas that it would be impossible to mention them all. Many can be found on the company's website or in a "Press Clips" book they produce. Sources of positive publicity include Time Magazine (September, 2005), Virgin Blue (April, 2005), Bel-AirView (July, 2005),Lucky Magazine about Shopping (March, 2005), Shop Til You Drop (July, 2005) Real Magazine (May, 2005), Spa 20/20 (January, 2005), Healing Lifestyles (January, 2005), ELLE (July 2005), Breathe (May, 2005), Destinations Weddings and Honeymoons (March, 2005), Fit Yoga (December, 2004) Parents Magazine (May 2005), American Spa (January, 2006), Shop Til You Drop (January, 2005), Family Circle (July, 2005), New Zealand Beauty (October, 2005), Pacific Power (May, 2005), Spa Finder (February, 2006),Spa Review (January, 2006), Vogue (july, 2004), ELLE (July, 2004), Us (June, 2004), Spa Healthy Living Travel and Renewal (October, 2004), Bazaar (October, 2004, August, 2004 and May, 2004), American Spa (July 2004), Cosmopolitan (April, 2004), 2001: US Fox News International listed its products in its top 10 best buys as a Christmas gift, and many others. Most of these articles can be viewed online at www.purefiji.com/press.

\section{OTHER HONORS}

- 2001: Pure Fiji's skincare products were presented as gifts to winners in the Grammy Musicals.

- 2002: Pure Fiji was invited to participate among a small elite group of skin care companies in the PreEmmy Award activities and provided a complimentary gift basket to each nominee

- 2003: Golden Globe Awards pre-ceremony salon for nominees

\section{CRITICAL ISSUES AND CONCLUSION}

Pure Fiji Export Limited is in the spotlight; in a span of about six years the company has gained amazing publicity, wining the Prime Ministers Exporter Award twice, selected as a gift-provider for Grammy, Emmy, and Golden Globe nominees and special guests. PureFiji was also listed as one of the top 10 Christmas gifts in 2002 from US Fox News International. The demand for the product has increased dramatically and expansion of the factory was becoming essential. Their distribution outlets have also increased as prestigious stores compete to stock 
their products. Their on-line sales have increased, especially to the lucrative United States market, and this has required rapid upgrades to their webpage with new products.

Andree commented that they have been forced to increase their product range, as an increasing number of happy customers demand other skincare products. "We did not want to get into facial care products but our customers want them so we will provide them," says Andree. These products have subsequently been developed and placed on the market. Their initial acceptance in the American market has been so enthusiastic, that there have been inadequate initial supplies for Fiji!

Pure Fiji Limited is a real entrepreneurial company in the sense that its structure is not formalised. It has been developed and managed with a strong and accurate intuition, rather than detailed planning. Gaetane highlights this when she states that they do not have a business plan, marketing plan or annual reports. They mortgaged two properties to raise funds for their factory. All profits have been ploughed back into the business to expand. When a financial institute offered to buy shares, they rejected the idea as they want the company to remain a family business. "We have worked hard and we do not want other people getting the advantage of our hard work." It is a family passion.

As the company continues to rapidly grow, the Austin family will have to decide on a long-term growth strategy. This will require a more formalised structure and more detailed longer-term planning, especially as new competitors enter the market and try to imitate what they are already doing. Their unique combination of family talents, dedication to quality, dedication to environmentally friendly products and processes, to development of local low-income women, and to supplier, distributor, and employee relationships, along with their flair for low-cost but highly attractive product design and packaging, has given them a competitive advantage. This edge clearly needs to be maintained.

\section{CASE USE RECOMMENDATIONS}

This case is ideal for use in a new venture creation or entrepreneurship course, but would also be worthwhile in international marketing, service management, and strategic management courses. Interesting aspects that students can explore include product design, environmental focus, HRM practices in a developing country, packaging, international marketing including the use of e-commerce as a primary method of international sales, product positioning, entrepreneurial characteristics of the owners/managers, small venture growth and strategic planning issues.

\section{ACKNOWLEDGEMENTS}

With research assistance from Sonal Singh.

\section{REFERENCES}

1. Austin, A. 2002. Director. Pure Fiji Export Limited, Suva. Personal Communications

2. Austin, A. 2003. Director, Pure Fiji Export Limited, Suva. Personal Communications

3. Austin, G. 2002. Director. Pure Fiji Export Limited, Suva. Personal Communications

4. Austin, G. 2003. Director. Pure Fiji Export Limited, Suva. Personal Communications

5. $\quad$ Chaudhari, A. 2002. Harnessing Local Skills. The Review, February, 18.

6. Gremler, D.D., Gwinner, K.P., Brown, S.W. 2001. Generating Positive Word-of Mouth Communication through Customer-Employee Relationship. International Journal of Service Industry Management. Vol. 12, No1, Pg. 44-59.

7. Kavaliku, L.2000. Culture and Sustainable Development in the Pacific, In Hopper. A. (ed.), Culture and Sustainable Development in the Pacific. The National Centre for Development, Canberra.

8. Kuratko, D.F., Hodgetts, R.M. 2001. Entrepreneurship -A Contemporary Approach. $5^{\text {th }}$ Edition. Harcourt College Publishers, Orlando.

9. Pure Fiji Limited, Pure Fiji Home Page http://www.purefiji.com (14 October 2002) 
10. Yoffie, D.B and Michael, A.C. 1999. Judo Strategy - The Competitive Dynamics of Internet Time. Harvard Business Review, January-February, Pg. 71-81.

\section{NOTES}

